\title{
Solução do Problema de Pêndulo Oscilante com o Método das Diferenças Finitas
}

\author{
Gabrielle Piezzoti Oliveira* $^{*} \quad$ Adilandri Mércio Lobeiro \\ Departamento Acadêmico de Matemática, UTFPR \\ 80230-901, Campus Campo Mourão, Campo Mourão, PR \\ E-mail: gabrielle793@hotmail.com, alobeiro@utfpr.edu.br
}

\section{Clicia Geovana Alves Pereira Juan Amadeo Soriano Palomino \\ Departamento de Ciências, UEM \\ 87360-000, Campus Goioerê, Goioerê, PR \\ E-mail: cgapereira2@uem.br, jaspalomino@uem.br}

\section{RESUMO}

Praticamente todos os engenheiros são confrontados por problemas relacionados ao movimento periódico de corpos livres. Um exemplo simples é um pêndulo oscilante, onde uma partícula de peso $W$ está presa a uma haste sem peso, de comprimento $l$. Quando a partícula é solta, formando um ângulo inicial $\theta_{0}$ com a vertical, oscila de um lado para o outro com período $T$ [1]. As únicas forças agindo na partícula são a gravidade $g$ e a tensão $R$ na haste, como apresentado na Figura 1.

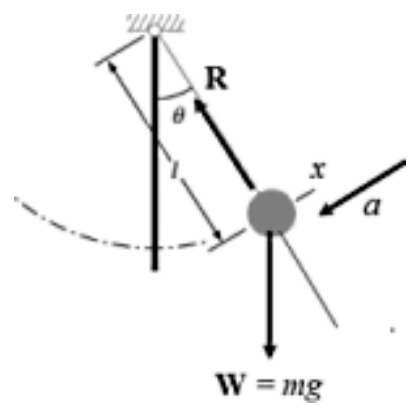

Figura 1: Pêndulo Oscilante

Ao aplicar as Leis de Movimento de Newton, deduz-se a seguinte Equação Diferencial Ordinária (EDO)

$$
\frac{d^{2} \theta}{d t^{2}}+\frac{g}{l} \sin \theta=0
$$

em que $\theta$ é o ângulo de deslocamento do pêndulo [1]. Observa-se que a massa $m$ não aparece na equação, pois o movimento de um pêndulo não depende de sua massa.

A equação (1) é uma EDO Não-Linear, pela presença do termo $\sin \theta$, o que impõe dificuldades para se obter sua solução analítica. Para pequenos deslocamentos angulares, no entanto, $\sin \theta$ é, aproximadamente, $\theta$, sendo este expresso em radianos. Portanto, nesse caso, a equação (1) se torna linear e assume a forma

$$
\frac{d^{2} \theta}{d t^{2}}+\frac{g}{l} \theta=0
$$

\footnotetext{
*bolsista de Iniciação Científica PICME, CNPq/Capes
} 
O objetivo deste trabalho é obter as soluções analítica e numérica de um Problema de Valor de Contorno (PVC) para um estudo de caso de um Pêndulo Oscilante. Para isso, considera-se $l=0.6096 \mathrm{~m}, g=9.800665 \mathrm{~m} / \mathrm{s}^{2}$ e as condições de contorno $\theta(0)=\pi / 8$ e $\theta(10)=\pi / 8$.

Obtém-se então o PVC

$$
\begin{array}{ccc}
\frac{d^{2} \theta}{d t^{2}} & = & -\frac{g}{l} \theta \\
\theta(0) \frac{\pi}{8} & \text { e } & \theta(10)=\frac{\pi}{8}
\end{array},
$$

cuja solução analítica é

$$
\theta(t)=-\frac{1}{8}\left(\frac{\pi\left(\cos \left(\frac{\sqrt{402175607}}{500}\right)-1\right) \sin \left(\frac{\sqrt{402175607 x}}{5000}\right)}{\sin \left(\frac{\sqrt{402175607}}{500}\right)}\right)+\frac{\pi}{8} \cos \left(\frac{\sqrt{402175607} x}{5000}\right) .
$$

Para a solução numérica, o algoritmo em MATLAB usado, que implementa o Método das Diferenças Finitas, é dado a seguir.

Código 1: Método de Diferenças Finitas - MATLAB

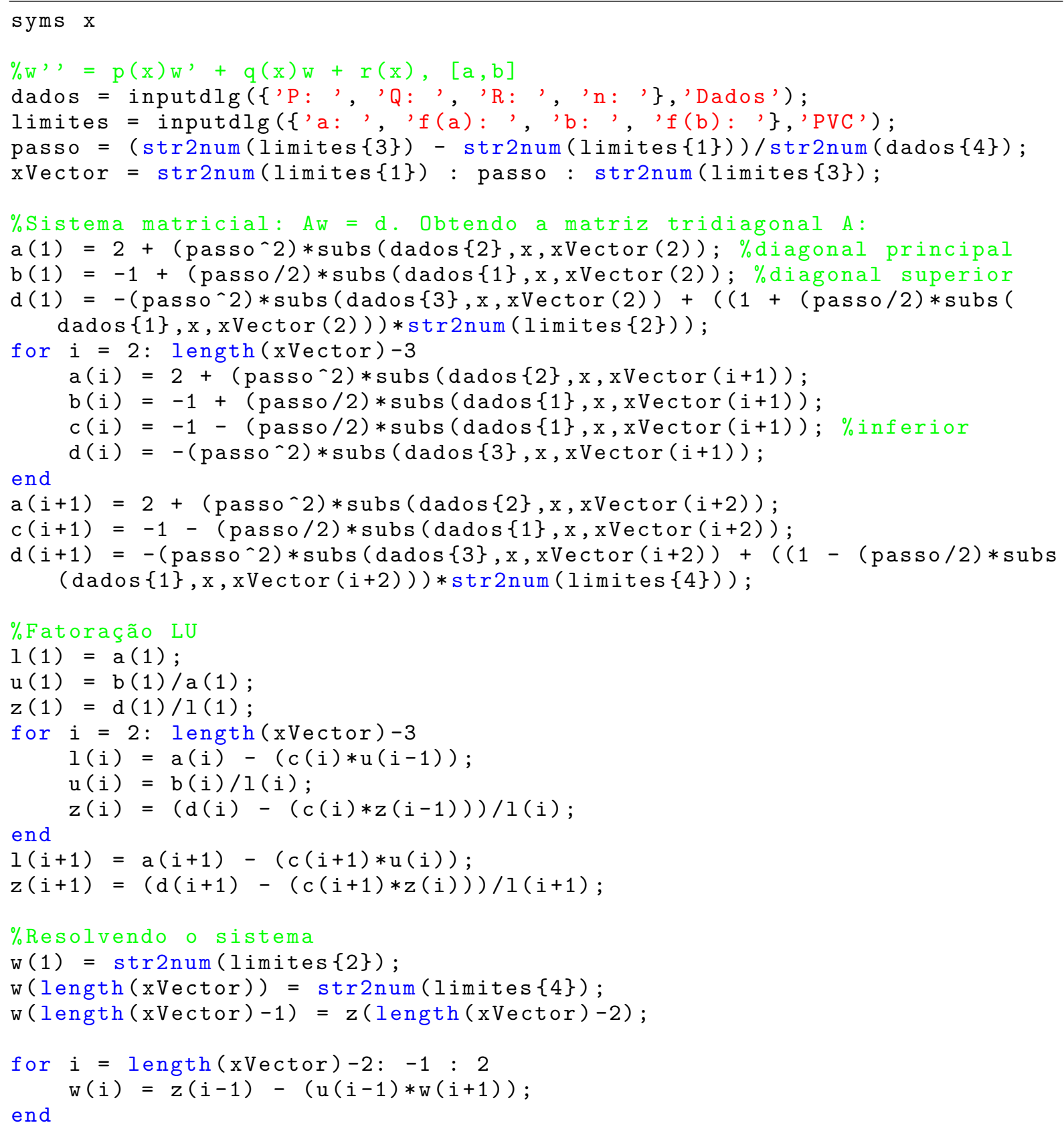


A ideia do Método é substituir as derivadas da EDO pelas fórmulas de Diferenças Centradas. O intervalo trabalhado é discretizado, no caso, para $[0,10]$ foi usado passo $h=0.01$, formando um sistema de equações de ordem $999 \times 999$ para as aproximações $\theta_{i}$ em cada um dos pontos. O algoritmo gera esse sistema, cuja matriz de coeficientes é tridiagonal e, para sua resolução, aplica Fatoração LU [2].

A Figura 2 apresenta os gráficos de ambas as soluções.

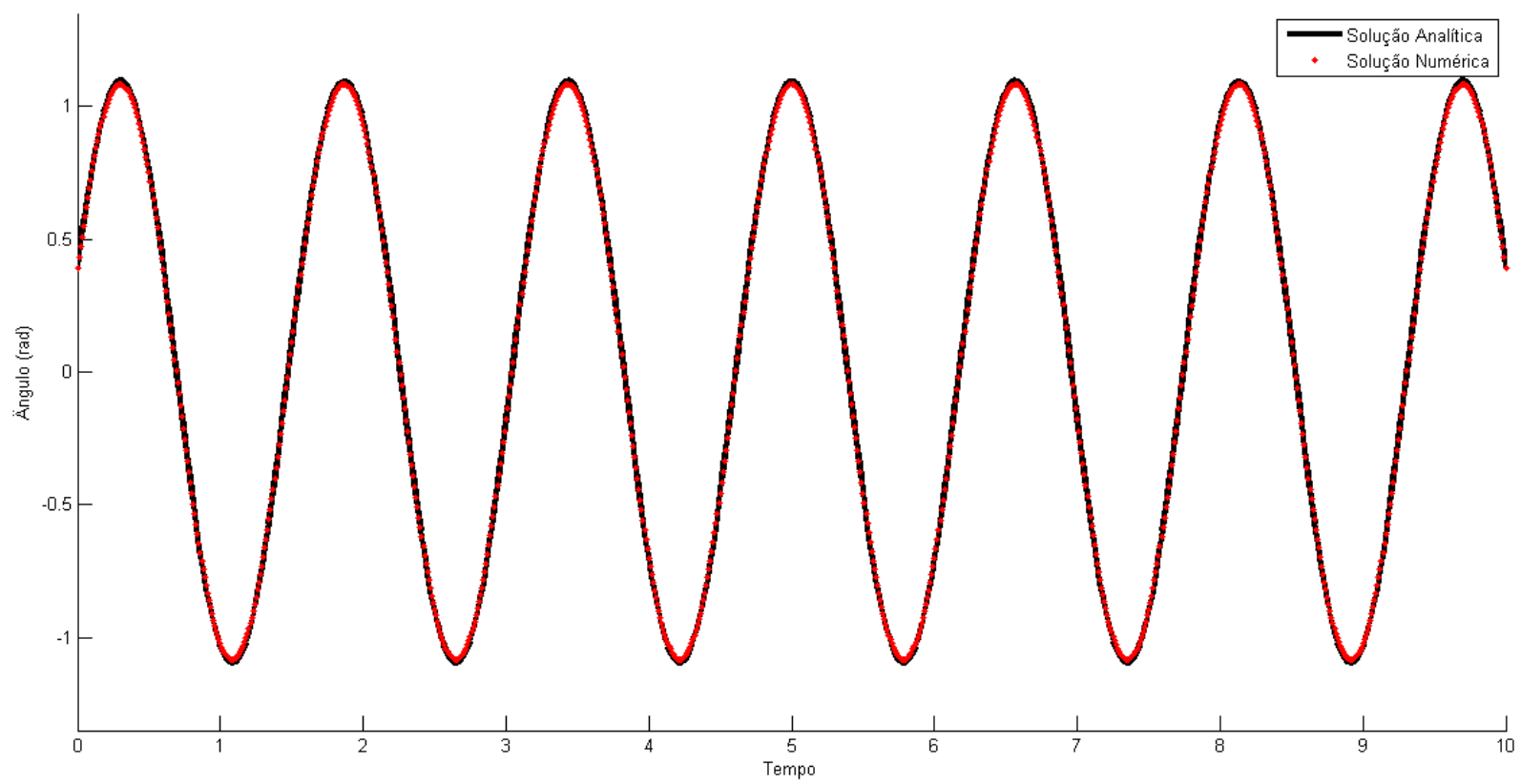

Figura 2: Soluções Gráficas

Com as soluções gráficas fica claro a proximidade entre os valores numéricos e os analíticos. A Tabela 1 apresenta uma comparação mais clara para alguns dos pontos calculados.

Tabela 1: Resultados e Erro

\begin{tabular}{ccccc}
\hline$i$ & $x_{i}$ & $\theta_{i}$ & $\theta\left(x_{i}\right)$ & Erro absoluto \\
\hline 0 & 0 & 0.3926990817 & 0.3926990817 & 0 \\
200 & 2 & 0.9313500208 & 0.9445509565 & 0.0132009357 \\
400 & 4 & -0.7001842363 & -0.7081023307 & 0.0079180944 \\
600 & 6 & -0.7001842363 & -0.7081023307 & 0.0079180944 \\
800 & 8 & 0.9313500208 & 0.9445509565 & 0.0132009357 \\
1000 & 10 & 0.3926990817 & 0.3926990817 & 0 \\
\hline
\end{tabular}

O método provou sua eficiência, pois realmente aproximou a solução numérica à analítica.

Palavras-chave: Equação Diferencial Ordinária, Solução Numérica, Diferenças Finitas, Pêndulo

\section{Referências}

[1] P. Tipler, G. Mosca, Física para cientistas e engenheiros, Volume 6, (LTC) pp. 396, 409-411, São Paulo, 2009.

[2] R.L. Burden, J.D. Faires, Análise Numérica, Cengage Learning, 2008. 